\title{
Doppler Sonographic Findings in Testicular Microlithiasis
}

\author{
Selim Serter, Sebnem Orguc, Bilal Gumus, Veli Ayyildiz, Yuksel Pabuscu
}

Department of Radiology (SS,SO,YP) and Department of Urology (BG), Celal Bayar University, Manisa, Turkey, and Manisa Military Hospital (VA), Manisa, Turkey

\begin{abstract}
Objective: The aim of this prospective study was to compare the resistive index (RI) values, which is a parameter of testicular parenchymal perfusion, in testicular microlithiasis (TM) cases and normal cases.

Materials and Methods: 2179 volunteers, all healthy men (17-42 years of age) from the Annual Army Reserve Officer Training Corps training camp were included in the study. A screening scrotal ultrasound was performed and all men diagnosed with TM underwent a scrotal Doppler ultrasonography scan (US). US examinations were performed for subjects with TM and without TM as a control group and RI was determined.

Results: 53 men with TM were identified in the 2179 US. Spectral Doppler examination was applied to 50 randomly selected cases (100 testicles) without TM and 92 testicles with TM, 39 cases (78 testicles) with bilateral and 14 cases with unilateral involvement. However, 48 normal testicles (17 bilateral and 14 unilateral) and 47 testicles with TM (15 bilateral and 17 unilateral, 10 of which were cases with bilateral TM) where flow from the centripetal artery could be obtained and analyzed were included in the statistical analysis for resistive indices. There was no significant difference regarding the RI and spectral examinations between subjects with and without TM. An interesting finding was the twinkling artifact observed in three cases.

Conclusion: Microliths did not alter the RI values and thus had no influence on testicular perfusion on Doppler US examination.
\end{abstract}

Key words: testis, ultrasonography, lithiasis, Doppler

Int Braz J Urol. 2008; 34: 477-84

\section{INTRODUCTION}

Testicular microlithiasis (TM) is an uncommon condition characterized by intratubular calcifications within a multilayered envelope usually discovered incidentally at ultrasonography (US) $(1,2)$. Although minor microcalcification within a testis is considered normal, the typical US appearance of TM is of multiple nonshadowing echogenic foci measuring 2-3 $\mathrm{mm}$ and randomly scattered throughout the testicular parenchyma. The clinical significance of testicular microlithiasis remains unclear. Currently there is no evidence that TM is either a premalignant condition or a causative agent in testicular neoplasia; however, it has been associated with testicular neoplasia in $18-75 \%$ of cases (3-7). Some authors concluded that the increase in the relative risk of testicular cancer in the group with TM suggests that the presence of $\mathrm{TM}$ in symptomatic men is clinically significant. In contrast, de Castro et al. recently reported only 1 case of germ cell tumor detected in the 5 year follow-up of 63 subjects with TM suggesting US follow-up would do little to improve outcomes associated with testicular cancer and they continued to recommend 
testicular self-examination in men at risk (8). It is by no means certain that microlith on its own is predictive of tumor.

Doppler US features of the testes, especially resistive index (RI), which is a reflection of arterial impedance, have been used to evaluate several testicular disorders, such as varicocele, orchitis, scrotal hernias, and others (9-11). Currently, RI has become a diagnostic tool of testicular blood flow in many diseases as established by Middleton et al. (12). Among numerous Doppler US studies of the testes previously published, only two case reports attempted to identify Doppler ultrasonographic parameters for TM, however encountered no specific findings $(13,14)$. This is the first study, to our knowledge, to investigate the Doppler parameters of TM in a large cohort and comparing them with a control group.

The aim of this prospective study was to compare the RI values, which is a parameter of testicular parenchymal perfusion in subjects with or without TM.

Many new studies have addressed the fact that hypoxic stress contributes to many (patho) biological disorders and hypoxic control of cell growth and death may be of general pathophysiological importance $(15,16)$. On these bases, we attempted to evaluate the possible vascular alterations in TM with the hypothesis of compression of microliths leading to increased local pressure in the testicular parenchyma and the possible association of microliths and tumor formation.

\section{MATERIALS AND METHODS}

Between August 2002 and May 2003, 2,179 healthy volunteers from Reserve Officer Training Corps annual training camp were included in the study. A total of 2,179 white male subjects were evaluated by US. The age of the subjects (mean \pm SD) was $22.4 \pm 3.6$ years (range 17-42 years). There was no racial variation in our study cohort. Informed consent was obtained from all participants. The study was approved by the Institutional Review Board and met all guidelines of our institution. A medical history was obtained from all volunteers, who also underwent a genitourinary physical examination. None of the subjects had a urinary disease or any other pathology. Subjects underwent screening scrotal ultrasound with Siemens Sonoline G 50 ultrasound machine (Issaquah, WA). Examinations were performed with the patient in supine position and the scrotum was supported by a towel placed between the thighs and the penis was placed on the abdomen and covered with a towel. The ultrasound gel was warmed with a heated towel before sonography to avoid cremasteric muscle contraction. All examinations were performed using a 10-12 MHz linear array transducer in longitudinal and transversal sections to document the presence or absence of TM. Four different radiologists perform the screening B mod ultrasound. Subsequently the same experienced radiologist (SS) performed the Doppler US examination for cases with TM and the selected control group.

As previously defined, a testicular microlithiasis diagnosis was confirmed when more than 5 high intensity signals 1 to $2 \mathrm{~mm}$ in size without acoustic shadowing was detected by US in a testicle (Figure-1). We recorded if the testicles were involved with calcifications unilaterally or bilaterally. The cases with TM were not graded according to the severity of microliths. All men diagnosed with TM underwent testicular Doppler US examination, complete clinical evaluation including a detailed genitourinary history and physical examination and determination of tumor markers (Beta-HCG, AFP and lactate dehydrogenase). Color Doppler US of the scrotum was performed with the same equipment. All Doppler examinations were performed using the same linear array transducer with a range of Doppler frequency 5-7 MHz. Color gain (threshold) was maximized for optimal sensitivity while avoiding excessive color noise. The Doppler scale (range of displayable Doppler frequency shifts) was decreased to its lowest value to maximize sensitivity to slow flow. The Doppler scale was displayed on the right side of all images as a bar containing the red and blue color assignment for different Doppler frequency shifts. Wall filters were adjusted to the lowest possible value. In Doppler examinations resistive indices were obtained from the centripetal artery or its recurrent rami, whichever was visualized optimally. RI was calculated as defined (difference of peak systolic velocity and end diastolic velocity 
divided by peak systolic velocity). The RI was measured three times on each testicle.

Data were analyzed using SPSS 11.5 for Windows commercially available computer software. We used independent samples $t$ test and $p<0.05$ was accepted as statistically significant.

\section{RESULTS}

Fifty-three men with TM were identified in 2179 men, with a prevalence of $2.4 \%$ for TM in this asymptomatic population. The mean age \pm SD of subjects with TM was $23.9 \pm 4.2$ years old (range 20 to 31$), 39$ of the $53(73 \%)$ subjects had bilateral microlithiasis. All cases with microliths displayed diffuse type of TM and no cases of focal TM were detected. All subjects with TM had a normal genitourinary history and physical examination. The tumor markers were within normal limits for all subjects.

Spectral Doppler examination was applied to 50 randomly chosen cases (100 testicles) without TM and 92 testicles with TM, 39 cases (78 testicles) with bilateral and 14 cases with unilateral involvement. However, 48 normal testicles (17 bilateral and 14 unilateral) and 47 testicles with TM (15 bilateral and 17 unilateral, 10 of which were cases with bilateral TM) in which flow from the centripetal artery could be obtained and analyzed were included in the statistical analysis for resistive indices. The percentage of cases where RI could be obtained from the centripetal arteries were approximately the same in both TM and control groups. Resistive indices of subjects with and without TM are shown in Table-1. No finding specific to TM was detected on spectral Doppler ultrasound examination. There was no significant difference regarding the RI's and spectral examinations between subjects with or without TM. Figure-2 demonstrates Doppler spectral analysis of cases with testicular microlithiasis. An additional interesting finding detected during the Color Doppler examination was the twinkling artifact caused by testicular microliths (Figure-3). These artifacts were observed in only three of all cases with TM (5.6\%). These artifacts also complicated the examination by mimicking vascular structures while obtaining the Doppler spectrum.

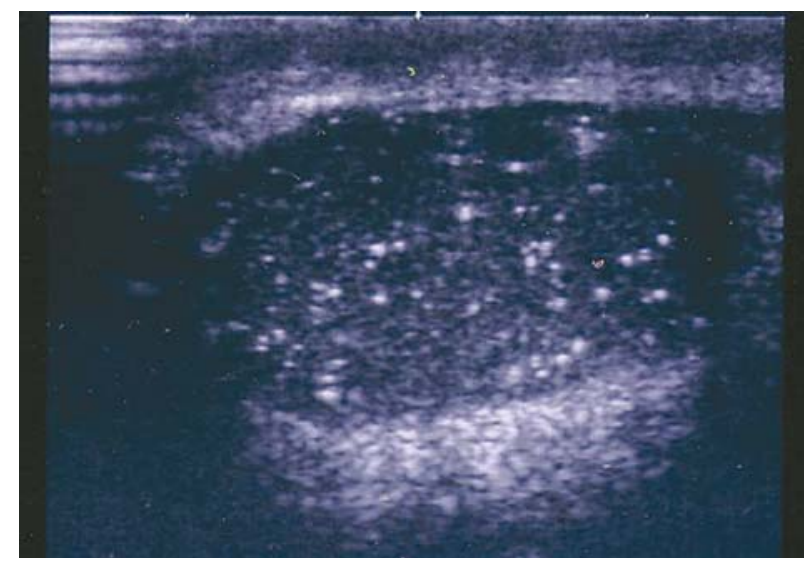

Figure 1 - Longitudinal sonogram of the testicle shows numerous, small, echogenic, foci of calcification without posterior shadowing.

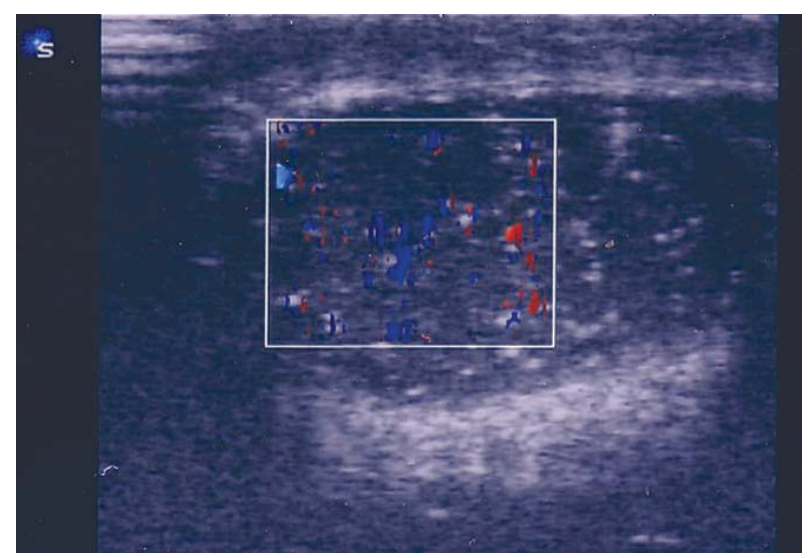

Figure 2 - Spectral Doppler analysis of testicular artery demonstrates resistive index value.

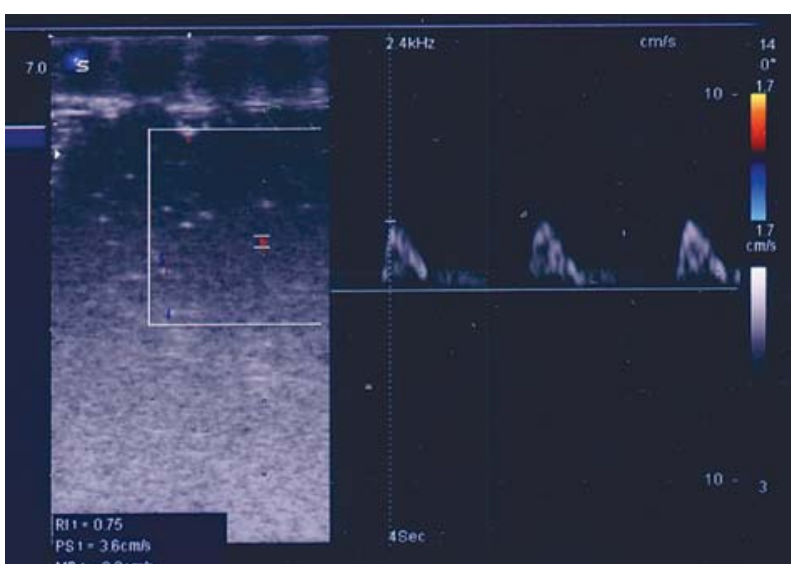

Figure 3 - Color Doppler sonograms shows twinkling artifact appears as rapidly alternating red and blue color Doppler signal behind the microliths. 
Table 1 - Resistive index values of centripetal artery or its recurrent rami transmediastinal testicular artery in subjects with or without testicular microlithiasis.

\begin{tabular}{lc}
\hline & Resistive Indices (mean \pm SD) \\
\hline With microlithiasis $(\mathrm{n}=48$ testes $)$ & $0.72 \pm 0.12$ \\
Without microlithiasis $(\mathrm{n}=47$ testes $)$ & $0.71 \pm 0.1$ \\
$\mathrm{p}$ Value & $>0.05$ \\
\hline
\end{tabular}

\section{COMMENTS}

TM is a rare, asymptomatic disease, suspected to be associated with various benign and malignant urological pathologies and genetic anomalies, usually found incidentally on ultrasound examinations performed for other reasons. TM has a characteristic appearance, classically consisting of multiple, often bilateral microliths scattered throughout the testicular parenchyma. Histologically microliths consist of a central calcified core surrounded by concentric laminations of cellular debris, glycoprotein and collagen (17).

Many new studies have reported that hypoxic stress contributes to many (patho) biological disorders and hypoxic control of cell growth and death may be of general pathophysiological importance $(15,16)$. On these bases, we attempted to evaluate the possible vascular alterations in TM with the hypothesis of compression of microliths leading to increased local pressure in the testicular parenchyma and the possible association of microliths and tumor formation.

This study is the first series that evaluated TM using Doppler ultrasound in a large cohort. There are only two case reports in the literature regarding the Doppler ultrasonographic findings of TM $(13,14)$. Knowledge of the arterial supply of the testis is required for interpretation of color flow Doppler sonography of the testis. The testicular arteries arise from the anterior aspect of the aorta just below the origin of the renal arteries. They course through the inguinal canal with the spermatic cord to the postero-superior aspect of the testis. Upon reaching the testis, the testicular artery divides into branches, which pierce the tunica albuginea and divides over the surface of the testis in a layer known as the tunica vasculosa. Centripetal branches arise from these capsular arteries; these branches course along the septula to converge on the mediastinum. From the mediastinum these branches form recurrent rami that course centrifugally within the testicular parenchyma, where they branch into arterioles and capillaries (18). The velocity waveforms of the normal intratesticular arteries show high levels of antegrade diastolic flow throughout the cardiac cycle, reflecting the low vascular resistance of the testis (12). In this study cohort we evaluated the intratesticular artery (centripetal arteries and its recurrent rami) flow parameters. It is suggested that the resistive indices could be higher in patients with TM due to compression of the intratesticular arteries by the microliths. However, we did not find any differences regarding the Doppler parameters between subjects with or without TM, as reported by Kutlu et al. (14). All Doppler parameters and spectral examination findings were within normal limits in both groups.

An interesting finding was the twinkling artifact seen in three cases. Twinkling artifact was described by Rahmouni et al. (19) as an artifact generated by a strongly reflecting medium. Twinkling artifact appears as a rapidly alternating red and blue color Doppler signal behind certain stationary objects, which gives the appearance of movement. Since its initial description the twinkling artifact has been reported mainly in association with urinary tract calculi (20-22). Recently twinkling artifact has been described behind calcifications in various tissues, such as gallbladder stones, encrustated indwelling ureteral stents, strongly reflecting orbital structures, a calcified liver mass, intestinal pneumatosis and an intracranial microcoil (22-27). This finding has not been previously reported for TM. These artifacts secondary to 
hyperechoic microliths have created difficulties in obtaining the Doppler spectral analysis of intratesticular branches.

All subjects with TM were followed-up throughout their military service. At 6 and 12 months of follow-up, the subjects with TM were re-evaluated with a physical examination, testicular tumor markers and scrotal US examination. None of the subjects with TM underwent the biopsy procedure since there were no findings suggesting a testicular tumor such as a hypoechoic area or an irregularity on testicular contour. No testicular tumor was detected during the diagnosis or follow-up.

In conclusion, Doppler ultrasound in TM, previously reported only as case studies in the literature, did not alter the spectral analysis parameters, and thus had no influence on testicular perfusion in Doppler US examination. Additionally we described the twinkling artifact, a misleading finding creating difficulty in spectral analysis secondary to microliths, which has not been reported in TM in the literature.

\section{CONFLICT OF INTEREST}

None declared.

\section{REFERENCES}

1. Janzen DL, Mathieson JR, Marsh JI, Cooperberg PL, del Rio P, Golding RH, et al.: Testicular microlithiasis: sonographic and clinical features. AJR Am J Roentgenol. 1992; 158: 1057-60.

2. Backus ML, Mack LA, Middleton WD, King BF, Winter TC 3rd, True LD: Testicular microlithiasis: imaging appearances and pathologic correlation. Radiology. 1994; 192: 781-5.

3. Jaramillo D, Perez-Atayde A, Teele RL: Sonography of testicular microlithiasis. Urol Radiol. 1989; 11: 55-7.

4. Höbarth K, Susani M, Szabo N, Kratzik C: Incidence of testicular microlithiasis. Urology. 1992; 40: 464-7.

5. Middleton WD, Teefey SA, Santillan CS: Testicular microlithiasis: prospective analysis of prevalence and associated tumor. Radiology. 2002; 224: 425-8.

6. Patel MD, Olcott EW, Kerschmann RL, Callen PW, Gooding GA: Sonographically detected testicular microlithiasis and testicular carcinoma. J Clin Ultrasound. 1993; 21: 447-52.

7. Serter $S$, Gümüs $B$, Unlü $M$, Tunçyürek $O$, Tarhan S, Ayyildiz V, et al.: Prevalence of testicular microlithiasis in an asymptomatic population. Scand J Urol Nephrol. 2006; 40: 212-4.

8. DeCastro BJ, Peterson AC, Costabile RA: A 5-year followup study of asymptomatic men with testicular microlithiasis. J Urol. 2008; 179: 1420-3; discussion 1423.

9. Tanriverdi O, Miroglu C, Horasanli K, Altay B, Caliskan $\mathrm{KC}$, Gumus E: Testicular blood flow measurements and mean resistive index values after microsurgical and high ligation varicocelectomy. Urology. 2006; 67: 1262-5.

10. Ozturk A, Ozturk E, Zeyrek F, Onur K, Sirmatel O, Kat N: Comparison of brucella and non-specific epididymorchitis: gray scale and color Doppler ultrasonographic features. Eur J Radiol. 2005; 56: 256-62.

11. Turgut AT, Olçücüoglu E, Turan C, Kiliçoglu B, Kosar P, Geyik PO, et al.: Preoperative ultrasonographic evaluation of testicular volume and blood flow in patients with inguinal hernias. J Ultrasound Med. 2007; 26: 1657-66; quiz 1667-9.

12. Middleton WD, Thorne DA, Melson GL: Color Doppler ultrasound of the normal testis. AJR Am J Roentgenol. 1989; 152: 293-7.

13. Yagci C, Ozcan H, Aytaç S, Aydos K, Atasoy C: Testicular microlithiasis associated with seminoma: Gray-scale and color Doppler ultrasound findings. Urol Int. 1996; 57: 255-8.

14. Kutlu R, Sigirci A, Baysal T, Alkan A, Sarac K: Effects of testicular microlithiasis on Doppler parameters: report of three cases. BMC Urol. 2002; 2: 3.

15. Sharifi N, Farrar WL: Perturbations in hypoxia detection: a shared link between hereditary and sporadic tumor formation? Med Hypotheses. 2006; 66: 7325.

16. Carmeliet P, Dor Y, Herbert JM, Fukumura D, Brusselmans K, Dewerchin M, et al.: Role of HIF-1alpha in hypoxia-mediated apoptosis, cell proliferation and tumour angiogenesis. Nature. 1998; 394: 485-90.

17. Vegni-Talluri M, Bigliardi E, Vanni MG, Tota G: Testicular microliths: their origin and structure. J Urol. 1980; 124: 105-7.

18. Middleton WD, Bell MW: Analysis of intratesticular arterial anatomy with emphasis on transmediastinal arteries. Radiology. 1993; 189: 157-60.

19. Rahmouni A, Bargoin R, Herment A, Bargoin N, Vasile $\mathrm{N}$ : Color Doppler twinkling artifact in hyperechoic regions. Radiology. 1996; 199: 269-71. 
20. Chelfouh N, Grenier N, Higueret D, Trillaud H, Levantal O, Pariente JL, et al.: Characterization of urinary calculi: in vitro study of "twinkling artifact" revealed by color-flow sonography. AJR Am J Roentgenol. 1998; 171: 1055-60.

21. Lee JY, Kim SH, Cho JY, Han D: Color and power Doppler twinkling artifacts from urinary stones: clinical observations and phantom studies. AJR Am J Roentgenol. 2001; 176: 1441-5.

22. Aytaç SK, Ozcan H: Effect of color Doppler system on the twinkling sign associated with urinary tract calculi. J Clin Ultrasound. 1999; 27: 433-9.

23. Ustymowicz A, Krejza J, Mariak Z: Twinkling artifact in color Doppler imaging of the orbit. J Ultrasound Med. 2002; 21: 559-63.

\footnotetext{
Correspondence address:

Dr. Selim Serter

317 sok $20 / 5$

Ucyol, Ýzmir, Turkey

Fax: + $90236237-0213$

E-mail: serterselim@gmail.com
}

\section{EDITORIAL COMMENT}

Testicular microlithiasis (TM) corresponds to intratubular calcifications resulting from degenerating cells within the seminiferous tubules. They can be located in the lumen or beneath the epithelium under a thin layer of connective tissue (1). They are well seen with Ultrasound, and occasionally and depending on the number of calcifications, on Computed Tomography.

One of the first reports on testicular microlithiasis was found in the context of pulmonary alveolar microlithiasis in 1970 (2). Microlithiasis has been found in the adult general population with a reported variable incidence of $2.4 \%$ (3) and $1.1 \%$ in children (4). It has also been observed in association with
24. Khan HG, Gailloud P, Martin JB, Khaw N, Spadola L, Rüfenacht DA, et al.: Twinkling artifact on intracerebral color Doppler sonography. AJNR Am J Neuroradiol. 1999; 20: 246-7.

25. Trillaud H, Pariente JL, Rabie A, Grenier N: Detection of encrusted indwelling ureteral stents using a twinkling artifact revealed on color Doppler sonography. AJR Am J Roentgenol. 2001; 176: 1446-8.

26. Ghersin E, Soudack M, Gaitini D: Twinkling artifact in gallbladder adenomyomatosis. J Ultrasound Med. 2003; 22: 229-31.

27. Oktar SO, Yücel C, Erbas G, Ozdemir H: Use of twinkling artifact in sonographic detection of intestinal pneumatosis. Abdom Imaging. 2006; 31: 293-6.

Accepted after revision: April 20, 2008

several other pathologies such as infertility (5), postorchiopexy (6), orchialgia (7), torsion of appendix testis (8), McCune-Albright syndrome (9) and Down syndrome (10). The main concern of testicular microlithiasis is its association with germ cell neoplasia and carcinoma in situ (11).

While microcalcifications do exist in roughly $50 \%$ of germ cell tumors, the majority of men with testicular microlithiasis will not develop testicular cancer. Increased emphasis on testicular examination is the recommended follow-up for men identified with this finding (12). Follow-up at this time should be dictated based on risk factors for developing testis cancer rather than on the presence of TM (13). 
The recent study on Doppler Sonographic Findings in Testicular Microlithiasis by Serter et al. published in the current issue of the Journal expands the understanding of TM.

\section{REFERENCES}

1. Smith WS, Brammer HM, Henry M, Frazier H: Testicular microlithiasis: sonographic features with pathologic correlation. AJR Am J Roentgenol. 1991; 157: 1003-4.

2. Coetzee T: Pulmonary alveolar microlithiasis with involvement of the sympathetic nervous system and gonads. Thorax. 1970; 25: 637-42.

3. Serter $S$, Gümüş B, Unlü M, Tunçyürek $O$, Tarhan S, Ayyildiz V, et al.: Prevalence of testicular microlithiasis in an asymptomatic population. Scand J Urol Nephrol. 2006; 40: 212-4.

4. Dagash H, Mackinnon EA: Testicular microlithiasis: what does it mean clinically? BJU Int. 2007; 99: 15760.

5. Schantz A, Milsten R: Testicular microlithiasis with sterility.Fertil Steril. 1976; 27: 801-5.

6. Mullins TL, Sant GR, Ucci AA Jr, Doherty FJ: Testicular microlithiasis occurring in postorchiopexy testis. Urology. 1986; 27: 144-6.
7. MacKinnon J: Testicular microlithiasis: echographic diagnosis of a new cause for orchialgia and infertility. Rev Med Chil. 1990; 118: 287-90.

8. Kwan DJ, Kirsch AJ, Chang DT, Goluboff ET, Berdon WE, Hensle TW: Testicular microlithiasis in a child with torsion of the appendix testis. J Urol. 1995; 153: 183-4.

9. Wasniewska M, De Luca F, Bertelloni S, Matarazzo P, Weber G, Crisafulli G, et al.: Testicular microlithiasis: an unreported feature of McCune-Albright syndrome in males. J Pediatr. 2004; 145: 670-2.

10. Vachon L, Fareau GE, Wilson MG, Chan LS: Testicular microlithiasis in patients with Down syndrome. J Pediatr. 2006; 149: 233-6.

11. Parenti GC, Zago S, Lusa M, Campioni P, Mannella P: Association between testicular microlithiasis and primary malignancy of the testis: our experience and review of the literature. Radiol Med (Torino). 2007; 112: 588-96.

12. Shichijo T, Sakamoto H, Saito K, Ogawa Y, Yoshida $\mathrm{H}$, Kushima M: Relevance of testicular microlithiasis to the testicular carcinoma in situ in the contralateral testicle. Nippon Hinyokika Gakkai Zasshi. 2007; 98: 541-6.

13. Rashid HH, Cos LR, Weinberg E, Messing EM: Testicular microlithiasis: a review and its association with testicular cancer. Urol Oncol. 2004; 22: 285-9.

\section{Dr. Eugenio O. Gerscovich University of California Davis Medical Center Sacramento, California, USA}

E-mail:eugenio.gerscovich@ucdmc.ucdavis.edu

ticular tumors during the 12-month follow-up period. Moreover, the authors compared the resistance index (RI) between men with and without TM in order to evaluate the relationship between TM and testicular perfusion, while also showing that TM did not alter testicular perfusion, which firstly showed based on the findings of a large cohort.

However, this study had some limitations as follows: 1) Various ultrasonographic diagnostic 
criteria were used in different studies including this study, which may thus have influenced the prevalence of TM. 2) While the etiology of TM has not yet been verified, TM may originate from the degeneration of seminiferous tubules. Therefore, TM itself may be associated with an alteration of testicular perfusions. Moreover, the number and distribution of microliths may be related to testicular perfusion. 3) The number of men with TM is small. In addition, a failure to measure the RI was observed in about one-half of all males with and without TM. These factors may thus have influenced the results and they may also be related to the impairment of testicular perfusion. Therefore, further study is necessary to verify the relationship between testicular perfusion and TM. 4) Few studies have so far shown what the measurement of RI means in healthy men. Unfortunately, comparisons of the RI findings between men with and without TM in order to elucidate the relationship between TM and testicular perfusion may not be informative for readers. I think that a study, which evaluates the testicular function including the semen profiles, may be more useful for elucidating the relationship between TM and testicular perfusion.

Finally, TM itself and testicular tumors have not yet been verified as a premalignant condition, while TM has been reported to be associated with testicular tumors and carcinoma in situ. Therefore, the necessity of regular follow-up in normal men with TM has not yet been conclusively proven.

Dr. Hideo Sakamoto Department of Urology, Showa University School of Medicine Tokyo, Japan E-mail: hs-showa-u@med.showa-u.ac.jp 